\title{
O FRACASSO ESCOLAR E A TEORIA DA SEMIFORMAÇÃO: CONSIDERAÇÕES PRELIMINARES ENTRE CHARLOT E ADORNO
}

\author{
Dalmo Cavalcante de Moura ${ }^{1}$
}

Faculdade São Tomás de Aquino - Facesta

Anderson de Alencar de Menezes ${ }^{2}$

Universidade Federal de Alagoas - UFAL

Resumo

Nesse artigo iremos problematizar a questão do Fracasso Escolar em Charlot e as possíveis relações com a Formação Integral de Adorno (1903-1969

Palavras-chave: Fracasso Escolar. Formação Integral. Experiência danificada.

\section{THE SCHOOL FAILURE AND THE THEORY OF SEMIFORMATION: PRELIMINARY CONSIDERATIONS BETWEEN CHARLOT AND ADORNO}

\begin{abstract}
In this article we will problematize the question of School Failure in Charlot and the possible relations with the Integral Formation of Adorno (1903-1969).
\end{abstract}

Keywords: School Failure. Integral Training. Experience Damaged.

\section{INTRODUÇÃO}

Na sociedade cada vez mais concorrencial o Fracasso Escolar tem chamado atenção dos pesquisadores em educação. Assim, tentamos abordar essa temática em um dos grandes teóricos do Brasil, o pesquisador francês Bernard Charlot (1944) ${ }^{3}$ radicado no Brasil já algum tempo. No nosso primeiro tópico buscamos explicar a problemática da origem do fracasso escolar. Uma das possíveis causas levantadas é a nova demanda de alunos e alunas que a escola tem atendido na atualidade. Em seguida discutimos o conceito propriamente dito de fracasso escolar. Afinal quem fracassa? A didática, a escola, a educação ou o alunado. O problema é bem complexo e exige a busca de suas causas. Essa é nossa discussão seguinte. Uma das hipóteses é de que o fracasso escolar tem relação direta com a reprodução social e a posição na

\footnotetext{
${ }^{1}$ Formado em Licenciatura em Filosofia pela UFAL (Universidade Federal de Alagoas). Mestre em Educação pelo Centro de Educação (CEDU/UFAL). Professor do Curso de Licenciatura em Filosofia da Facesta (Faculdade São Tomás de Aquino).

${ }^{2}$ Doutor em Ciências da Educação pela Universidade do Porto/Portugal. Professor da Universidade Federal de Alagoas (UFAL).

${ }^{3}$ Filosofo francês nascido em 1944. Desenvolve seu pensamento problematizando a questão do Fracasso Escolar, o Saber entre outros.
}

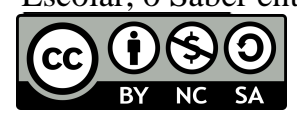

P2P \& INOVAÇÃO, Rio de Janeiro, v. 5 n. 1, p.89-101, Set./Fev. 2018. 
sociedade em que alunos e alunas ocupam. O penúltimo tópico com o titulo de: $\mathrm{O}$ fracasso escolar como Experiência Danificadana na Perspectiva da Escola de Frankfurt ${ }^{4}$. Argumentamos que as causas do fracasso escolar podem está na carência de uma Formação mais ampla, aquilo que Adorno chamava de Bildung (Formação Integral). No último tópico iremos tratar do fracasso escolar como uma experiência danificada presente nos processos formativos da atualidade como impossibilidade da subjetividade a favor da sociedade homogenia.

\section{AS ORIGENS HISTÓRICAS DO FRACASSO ESCOLAR}

Quando do inicio das pesquisas voltadas a essas temáticas fica claro que o parâmetro usado foi à comparação com os índices dos países do Leste da Europa e da America do Norte. As revoluções e o desenvolvimento do capitalismo marcaram a Europa do século XVIII, tais como a: Revolução Política Francesa (1789-1792) e a Revolução Industrial Inglesa que tem como marco a construção do sistema fabril na região de Lancashire. Com o desenvolvimento do capitalismo surge uma nova classe social que é o proletariado que vai sustentar a ordem de outra classe, a classe dominante - a burguesia. Nesse sentido, novos personagens vão entrar na roda da história: mercador, manufatureiro e o proletariado (vendedor de força de trabalho).

A grande maioria das revoluções aconteceram em virtude dos questionamentos da burguesia, assim, podemos dizer que a burguesia foi o motor da história, pois, foi ela que derrubou: regimes, acabou com monarquias, sistema feudal.

Diante do que aqui foi exposto de maneira bem rápida, pois, não teríamos como remontar os detalhes das mudanças frente ao novo sistema de produção instalado pelo capitalismo, nosso objetivo de estudo é o fracasso escolar, assim, tal exposição aqui serve apenas como pano de fundo para nossa analise. Com a instalação da grande indústria pelo sistema do capital faz-se necessário criar um novo sujeito para essa nova sociedade capitalista. Sendo assim, a educação também sofrerá as consequências do sistema capitalista.

\section{A REFLEXÃO DE CHARLOT SOBRE O FRACASSO ESCOLAR}

Em sua obra 'Da Relação com o Saber' Charlot (2000) reflete sobre as causas, ou possíveis causas do fracasso escolar. Afinal! Por que será que o fracasso acontece? Na busca por respostas de imediato acreditamos na relação direta dos aspectos econômicos, ou seja,

\footnotetext{
${ }^{4}$ Grupo de intelectuais interdisciplinar formado na Alemanha na década de 1920. São alguns dos seus teóricos: Theodor w. Adorno (1903-1969); Max Horkheimer (1895-1973).
} 
acreditamos que as crianças oriundas dos meios sociais mais populares (pobres, periferias) de maneira inata já trazem o fracasso consigo.

Poderíamos afirmar que essa perspectiva preconceituosa recai na concepção da corrente filosófica conhecida como Inatismo ${ }^{5}$, além de retomar certas concepções educacionais biologizantes ${ }^{6}$ das crianças oriundas dos meios populares. As pesquisas realizadas procuram a coleta de dados, mas, é preciso ir além disso, segundo Charlot (2000, p. 9):

Não basta, porém, coletar dados; deve-se também saber exatamente o que se procura. E isso é ainda mais necessário quando se aborda uma questão antiga de uma forma relativamente nova. Portanto, é precisamente esse o nosso objetivo. Estamos trabalhando sobre a questão do fracasso escolar, um campo saturado e teorias construídas e opiniões de senso comum.

As escolas recebem uma clientela cada vez maior de alunos que não conseguem e não conseguiram aprender, assim é impossível negarmos a existência do fracasso escolar. Mas quem fracassa é a escola? Quem fracassa é a didática? A escola em sua história sendo um lugar de formação de desenvolvimento da racionalidade e interação de certa forma tem colocado em silencio "os fracassados", isso ainda é um traço muito forte da tendência isoladora de tudo o que sai do esquadro, sai da linha de equilíbrio. A expressão fracasso escolar coloca em evidência a experiência, vivência e a prática, conforme Charlot (2000, p. 13-14):

\begin{abstract}
Dessa maneira, a noção de fracasso escolar é utilizada para exprimir tanto a reprovação em uma determinada série quanto a não-aquisição de certos conhecimento ou competências; refere-se, tanto aos alunos da primeira série do primeiro grau que não aprendem a ler em um ano, como aos que fracassam no "bacharelado", ou até no primeiro ciclo superior; ela se tornou, mesmo, tão extensão, que uma espécie de pensamento automático tende hoje a associa-lo à imigração, ao desemprego, à violência, à periferia.
\end{abstract}

Na problemática do fracasso escolar é necessário lembrar do componente ideológico que cerca esse problema. Primeiramente a discussão leva para o questionamento do que acontece na sala de aula, por que afinal as crianças não aprendem? O que acontece nesse bairro? O que acontece nessa instituição? A discussão também ganha aspectos mediáticos tais como: desafios profissionais, identitários, econômicos, socioeconômicos e sócio-econômicos.

Diante de toda essa discussão sobre o fracasso escolar um aspecto nos chama a atenção é o cuidado que devemos ter de não colocar a responsabilidade do fracasso escolar para uma categoria profissional especifica - o professor. A educação, enquanto serviço público tem sofrido uma demanda de responsabilidade até então, que não eram suas, as recentes prerrogativas de: educar para o meio ambiente, educar para diversidade, educar para o mercado

\footnotetext{
${ }^{5}$ É a concepção que as ideias, o conhecimento já nascem com os homens desde o nascimento, ou seja, não são adquiridos.

${ }^{6}$ É o pensamento que atribui uma seleção natural a partir da genética.
} 
de trabalho, educar para empreendedorismo..., são apenas algumas artimanhas de nossa contemporaneidade.

O Estado Liberal nos favorece com igualdade de direito pela disputa de um lugar ao Sol, assim, temos direito virtual à: educação, saúde, segurança..., mas, o que isso quer dizer mesmo? Que o individuo, o sujeito está por sua conta e risco, ou seja, ao mesmo tempo em que a sociedade cobra o preço do sucesso: profissional, econômico, interpessoal (as varias formas de redes sociais) não promove uma adequação de potencialização partindo do próprio individuo, ou seja, de sua própria realidade, conforme Charlot (2000, p. 14):

Enquanto inscritas em relações sociais de natureza diversa, prestam-se muito bem para um uso ideológico: o debate sobre o fracasso escolar enquanto desigualdade social pode ser desviado para questão da ineficácia pedagógica dos decentes... e vice versa.

Dessa maneira, o pesquisador deve ter cuidado na busca de uma resposta para a problemática do fracasso escolar, ou seja, se afastar da explicação mais imediata, como a o fracasso escolar ser originário única e exclusivamente da relação econômica.

Para Charlot (2000) a questão deve ser levada para a uma mudança, movimento, ou seja, não existe uma posição social pré-determinada e imutável, isso vai além da questão relação direta entre miséria/fracasso, ou pobreza/fracasso. O pesquisador francês defende que na verdade o que existe são alunos em situação de fracasso. Essa concepção é inovadora, pois, permite a ultrapassagem dos alunos em situação de fracasso escolar para alunos que em fïm dão certo na escola. Na teoria de Charlot o aluno em situação de fracasso escolar é o resultado de um falso problema teórico, ou seja, não existe o objeto aluno fracassado, segundo Charlot (2000, p. 16):

\footnotetext{
Existem, é claro, alunos que não conseguem acompanhar o ensino que lhes é dispensado, que não adquirem os saberes que supostamente deveriam adquirir, que não constroem certas competências, que não são orientados para habilitação que desejariam, alunos que naufragam e reagem com condutas de retração, desordem, agressão. É o conjunto desses fenômenos, observáveis, comprovados, que a opinião, a mídia, os docentes agrupam sob o nome de 'fracasso escolar.
}

Na verdade, essa é a resposta que a sociedade denomina para o conjunto de fenômenos que não é o fracasso escolar, mas o fracasso de toda sociedade, que na tentativa de padronizar um modelo de educação para diferentes composições sociais falha em sua função formadora.

O fracasso escolar mascará uma analise verdadeira que deveria ser feita, pois, alunos/as em situação de fracasso requer uma atenção, inovação de maneira diferenciada para enfrentar a carência de toda uma situação que compromete todo um processo distante das necessidades desses mesmos alunos/as. Para Charlot (2000) o que deve ser feito é uma analise da situação de 
fracasso escolar, observar as histórias escolares que terminam mal, o mesmo o fracasso escolar não é um objeto misterioso, ou um vírus resistente e imutável.

O fracasso escolar que é certa oposição ao que é: estático, equilibrado e continuo, revela uma: carência, necessidade que o sistema educacional não está preparado. O fracasso escolar enquanto situação requer assim um enfrentamento que sugere: movimento; busca, caminho ou processo de mudança para que o saber alcance aqueles que ainda não dominam o que é aceitável pela organização educacional. Os sistemas avaliativos se preocupam apenas com o êxito e a cada dia a questão da avaliação tem se tornado mais importante e a educação tem sido colocada em discussão na busca pelos índices que são comparados por: região, estados, municípios e até países. É necessário ir além da relação da posição que alunos/as ocupam na hierarquia das várias classes sociais presentes na sociedade, conforme Charlot (2010, p. 151):

Ele vive fora da escola formas de aprender que são muito diferentes daquelas que o êxito escolar requer. Essas contradições é que se deve tentar entender, Por isso, insisto muito sobre a heterogeneidade das formas de aprender na escola e, portanto, não se deve menosprezar esta instituição. Mas também se aprendem muitas coisas importantes fora da escola.

\section{AS CAUSAS DO FRACASSO ESCOLAR PARA CHARLOT}

Numa primeira perspectiva a sociologia dos anos 60 e 70 a problemática do fracasso escolar foi analisada tendo como pressuposto a questão da posição social.

Essa maneira de pesquisar o fracasso escolar, segundo Charlot (2000) não satisfaz a complexidade do problema de pesquisa. Essa analise está atrelada a sociologia da reprodução, conforme Charlot (2000, p. 20):

Mais precisamente ainda, Bourdieu raciocina em termos de sistemas de diferenças: às diferenças de posições sociais dos pais correspondem diferenças de posições escolares dos filhos e, mais tarde, diferença de posições sociais entre os filhos na idade adulta.

Essa relação não resolve de maneira completa o problema do fracasso escolar, mas, é inegável a sua contribuição. $O$ fracasso escolar vai além dessa relação tão direta como pensa a sociologia da reprodução. Nas camadas sociais mais baixas há uma busca também por ultrapassar as barreiras sociais impostas pelas condições: econômicas, moradia e posição dos pais na sociedade. A problemática do fracasso escolar vai além da profissão em que os pais se ocupam, segundo Charlot (2000, p. 22):

$\mathrm{Na}$ verdade, para essa reprodução (entendida como constatação) ocorrer, é preciso um trabalho, uma atividade, prática. A posição dos fillhos não é "herdada", à maneira de um bem que passasse de uma geração a outra por uma vontade testamental; ela é produzida por um conjunto de práticas familiares: as dos pais (que supervisionam os temas de casa, levam os filhos aos museus, a concertos, em viagens, levam-nos à aula de dança, ao tênis, etc) e as dos fillhos (os "herdeiros" sabem muito bem que não basta 
ser "filhos de" para ter sucesso na escola, mas que é preciso trabalhar, esforçar-se, esforçar-se muito).

É preciso levar em conta uma confluência de fatores tais como: a posição social (não como único fator); a singularidade da história dos indivíduos; o significado que os alunos/as atribuem à posição social; suas atividades (práticas); a especificidade dessa atividade. Atribuir a relação direta da posição social ao fracasso é esquecer a capacidade de mudança e espaços de movimento, mudança para ultrapassar a posição social que no momento ocupam. Atribuem-se aqueles que fracassam uma deficiência sociocultural, assim, a causa do fracasso escolar seria a deficiência, em segundo lugar a teoria do conflito cultural e em terceiro lugar a teoria da deficiência institucional. De diferentes maneiras estas teorias colocam sob o/a aluno/a ou sua origem familiar como a responsabilidade de suas dificuldades em aprender. Nessa concepção não existe a possibilidade do sucesso, pois, tais alunos/as estão fadados ao fracasso, essa é a atitude de "jogar a água junto com a criança", ou seja, uma precipitação, falta de atenção.

Deve-se para Charlot (2000) buscar saber o que faltou na origem da atividade para que o/a aluno/a no final apresentasse o conhecimento efetivo daquilo que foi proposto, o erro acontece pela tentativa de enxergar iguais toda uma coletividade, de acordo com:

Ao constatar-se uma "falta" no fim da atividade; essa falta é projetada, retroprojetada, para o inicio dessa atividade: faltam ao aluno em situação de fracasso recursos iniciais, intelectuais e culturais, que teriam permitido que o aprendizado (e o professor...) fosse eficaz. Ele é deficiente. (CHARLOT, 2000, p. 27).

De certa maneira remontar o percurso, onde foi que começou, essa falta, essa carência do aluno, ou seja, buscar o sentido da escola e dos próprios docentes, pois são vários casos de crianças dos meios populares que alcançam também o sucesso. O mais cômodo para explicar o fracasso escolar tem sido a leitura negativa da realidade social, isso implica atribuir ao outro, diferente da maioria dos/as alunos/as uma estática (sem movimento, mudança) de sua condição social, educacional e de posição.

Por outro lado, é necessário fazer uma leitura positiva daquilo que as pessoas fazem, conseguem, tem e são, e não somente aquilo que elas falham em suas carências, segundo Charlot (2000, p. 30):

A leitura positiva busca compreender como se constrói a situação de um aluno que fracassa em um aprendizado e, não, "o que falta" para essa situação ser uma situação de aluno bem-sucedido.

O processo de racionalização da modernidade e o desenvolvimento do capitalismo negaram as classes menos favorecidas uma formação que possibilitasse o conhecimento desalienante, fazendo assim, com que a educação fosse promotora de uma semiformação. 


\section{A SEMIFORMAÇÃO E FRACASSO ESCOLAR COMO ABANDONO DE UMA FORMAÇÃO CULTURAL}

Existe uma carência de uma formação mais ampla que possibilite uma abertura maior para inclusão de um saber que parta do cotidiano do aluno. A educação como tem sido organiza, vem alijando o alunado da possibilidade de se discutir a BIldung (Formação Integral), mesmo as reformas educacionais não alcançam esse aspecto que é um problema a ser enfrentado, segundo Adorno (2010, p. 8):

\section{Os sintomas do colapso da formação cultural que se fazem observar por toda parte, mesmo no estrato das pessoas mais cultas, não se esgotam com as insuficiências do sistema e dos métodos da educação, sob a crítica de sucessivas gerações.}

A preocupação com os aspectos extrapedagógicos é mínima, quando grande parte dos discursos atuais conhecem a problemática de uma educação que se distancia do aspecto extraescolar. A problemática da formação tem sido direcionada para uma semiformação que determina para a educação os processos seletivos para ingressar numa faculdade ou universidade ou ainda passar em um concurso e ser integrado no mercado de trabalho como o objetivo educacional. Sendo assim, a escola passa a ter uma responsabilidade que envolve vários aspectos sociais. Uma formação cultural possibilitaria uma alternativa para a educação comprometida com a adequação das pessoas a um mercado de trabalho, esquecendo que a educação é muito mais que isso, conforme Adorno (2010, p. 9):

\footnotetext{
A formação cultural, agora se converteu em uma semiformação socializada, na onipresença do espírito alienado, que, segundo sua gênese e seu sentido, não antecede à formação cultural, mas a sucede.
}

Sem um direcionamento para os aspectos culturais a educação não conseguirá explicar e abordar a questão do fracasso escolar, pois, antes de serem alunos, os sujeitos da educação vivem na sociedade, numa abrangência de relações sociais com os outros.

$\mathrm{Na}$ formação privilegiada pela educação, há um distanciamento daquilo que a escola ensina e daquilo que num espaço ampliado que é a sociedade, revela, os sujeitos buscam um movimento, mudança, tanto objetivo como é o caso de uma revolução ou espiritual (subjetividade) como é o caso da cultura, segundo Adorno (2010, p. 11):

\footnotetext{
Além disso, nos casos em que a formação foi entendida como conformar-se à vida real, ela destacou unilateralmente o momento da adaptação e impediu assim que os homens se educassem uns aos outros.
}

Há um campo de força que impulsiona uma formação dentro de uma tensão na busca pela hegemonia, assim foi na Alemanha nazista (1933-1945) que em nome do nacionalismo extremado, promoveu a perda da individualidade pela integração na massa amorfa da sociedade 
sem identidade. Dessa forma, a educação na Alemanha nazista serviu para domesticar o animal homem, alienando-se de si mesmo a favor daquilo que chamava a reconstrução do império germânico. Dessa maneira, a educação tem na atualidade o caráter de aprontar, para os exames, o concurso, a prova, que não se adéqua a esse regime não está pronto, por isso, fracassa, conforme Adorno (1995, p. 129):

Pessoas que se enquadram cegamente em coletivos convertem a si próprios em algo como um material, dissolvendo-se como seres autodeterminantes. Isto combina com a disposição de tratar outros como sendo uma massa amorfa.

Aqueles que fracassam estão fora do enquadramento estrutural daquilo que a escola exige, são indivíduos danificados, imperfeitos, incapazes de ter êxito no outro grau de ensino. O processo educacional é integrador, mas ao mesmo tempo despersonaliza o individuo de si mesmo, suas carências, necessidades não são objeto de alternativas de criação: metodológica, didática para que esses também alcancem o sucesso. A formação é desde sua origem delimitada pela tensão daqueles que dominam e aqueles que são submetidos a uma seleção, disputa de todos contra todos, assim, aquele que não alcança êxito na escola significa está em carências, falta com a sociedade que transformou a educação em mais uma mercadoria, ou seja, dos vários ideais de: liberdade, emancipação, solidariedade, racionalidade perdidos, pois, o que aconteceu realmente foi a formação degradada criando sujeitos fracos, reprimidos e degradados, segundo (ADORNO, 2010, p. 14):

O sonho da formação - a libertação da imposição dos meios e da estúpida e mesquinha utilidade - é falsificada na apologia de um mundo organizado justamente por aquela imposição.

Foi a formação para Adorno (2010) que garantiu ao burguês se tornar o empresário, gerente ou funcionário, sem a formação cultural, o burguês não teria desenvolvido economicamente e administrativamente e fortalecido seu poder de dominação. Essa foi uma carência do socialismo, pois, como a história revelou o proletariado só se reconhecia como categoria ligada diretamente com a economia, por outro lado, a burguesia era mais avançada subjetivamente, ou seja, também no aspecto espiritual (Cultural), conforme Adorno (2010, p.14):

Quando as teorias socialistas se preocuparam em despertar no proletariado a consciência de si mesmos, o proletariado não se encontrava, de maneira alguma, mais avançado subjetivamente que a burguesia. Não foi por acaso que os socialistas alcançaram sua posição chave na história baseando-se na posição econômica objetiva e não no contexto espiritual. 


\section{O FRACASSO ESCOLAR COMO EXPERIÊNCIA DANIFICADANA NA PERSPECTIVA DA ESCOLA DE FRANKFURT}

A Escola de Frankfurt faz uma crítica ao processo da racionalidade moderna que delimitou a capacidade humana, tendo em vista a predominância da razão instrumental que passa a organizar o processo do conhecimento. Sendo assim, é necessário afastar tudo o que traz desequilíbrio, ou seja, aquilo que não se encaixa, segundo Silva (2001, p. 41): “A filosofia de Horkheimer é quase sempre identificada como uma crítica à racionalidade instrumental, que encontraria no cientificismo contemporâneo sua versão mais contundente".

A escola não prepara o sujeito para potencializar a resistência necessária para se afirma enquanto subjetividade, assim, a escola homogeiniza a todos/as numa tentativa de alcançar a diversidades de alunos/as e suas carências a um só método didático.

$\mathrm{O}$ individuo no processo de racionalidade perde sua capacidade de se fazer-se em fim humano, ele passa a ser manipulado ao perder a consciência que reduz sua capacidade de imaginar e realizar o exercício do pensar. A educação tem sofrido a crise da razão objetiva e a razão subjetiva. Diante da sociedade administrada como educar? Educar para o mercado de trabalho? Educar para a cidadania? São algumas questões que se colocam na discussão atual da educação. A ciência educativa de certa maneira não sabe como aferir aqueles que não se adequam aos parâmetros da organização e classificação. Por outro lado, a sociedade administrada adia para sempre a satisfação das necessidades, conforme Silva (2001, p. 58): "Nesse contexto do liberalismo emergente, o individuo só pode manter seus interesses postergandopara um tempo longínquo a sua satisfação. Tal adiamento é garantido por meio de pequenas e efêmeras gratificações".

A racionalidade que prometeu libertar os homens trouxe como conseqüência a sua passividade. Assim, o modelo capitalista de produção, teve o sujeito necessário para suas prerrogativas, ou seja, o processo de racionalidade formou o futuro operário: autômato, obediente às regras e normas da sociedade de mercado, onde as emoções e espontaneidade devem se tornar impessoais. O sujeito, o individuo sob o regime do capitalismo passa a ser um ser humano castrado, castrado de suas emoções, subjetividade e capacidade imagética, sendo assim, um sujeito sem experiência, já que, para Silva (2001) o sujeito da sociedade capitalista é marcado pela incapacidade de experienciar o mundo, ao renunciar a si mesmo, segundo Silva (2001, p. 111):

Todo comportamento que pudesse transparecer sintomas de uma mimese incontrolada seria proscrito pela razão. A condição da civilização assenta-se sobre a garantia de que não haja retorno a comportamentos miméticos, portanto o progresso se teria dado 
sob o preço da repressão da mimeses e contra tudo aquilo que pudesse representar o não trabalho.

Na sociedade capitalista a educação será a instituição que se dirige a repressão da capacidade de mimeses, criando sujeitos disciplinados e harmônicos preparados para o trabalho anti-humano da fábrica. A escola nesse processo de racionalização na sua atualidade desenvolve uma relação de seleção dos alunos, criando através do fracasso escolar indivíduos atrofiados e frustrados, de acordo com Silva (2001, p. 189):

Em um mundo em que as pessoas não só carecem da Bildung, mas, mais do que isso, carecem das condições necessárias para experienciá-las, cabe à filosofia denunciar a incapacidade para a reflexão e a insensibilidade dela decorrente, configuradas na "feliz apatia" e na "frieza burguesa".

Apesar do avanço da área da comunicação, os sujeitos da sociedade administrada vivem num afastamento do contato com os outros, pois, vivenciam um novo tipo de individualismo, que não abre diálogo com a alteridade. Senso assim, o que resta para educação é uma tentativa de avaliar de maneira homogenia, sem discutir as particularidades daqueles que fracassam, segundo Adorno (1995, p. 122): "De uma perspectiva sociológica eu ousaria acrescentar que nossa sociedade, ao mesmo tempo em que se integrar cada vez mais, gera tendências de desagregação".

A formação aligeirada e os conteúdos coisificados que garantem uma participação na sociedade capitalista e no mundo do consumo numa pretensa sociedade de sujeitos livres e igualmente consumidores não permite uma formação que dasaliene e restaure a individualidade do pensamento autônomo e crítico, a final, todos são integrados a ilusão da Indústria Cultural. Sendo assim, o fracasso escolar é a crise da formação que promove uma experiência danificante dos sujeitos da educação, pois a subjetividade é negada pela sociedade administrada e impessoal, segundo Adorno (2010, p. 25):

\footnotetext{
A vida, modelada até suas últimas ramificações pelo principio da equivalência, esgota-se na reprodução de si mesma, na reiteração do sistema, e suas exigências descarregam-se sobre os indivíduos tão dura e despoticamente que cada um deles não pode manter-se firme contra elas como condutor de sua própria vida, nem incorporálas como algo específico da condição humana.
}

O que o sistema educacional juntamente com o capitalismo fazem é promover uma percepção danificada da realidade, portanto, as formas de acumulação de sensações e experiências não encontram relação da realidade e seus significados.

Dessa forma, é criada uma ilusão que afasta qualquer forma de aproximação do real com o que ele realmente é, pois, o sujeito se perde de si mesmo, já que, é preciso se adequar as realidade de não ser você mesmo, pois, o mundo da sociedade administrada não permite que o sujeito seja sujeito, mas, que entre em relação na massa amorfa e sem imaginação, desejo, ou 
querer próprio, ou seja, sem experiência genuína de ser sujeito particularizado, conforme Adorno (2010, p. 26):

Desse modo, a liberdade e a humanidade, em certo grau, perderam sua força resplandecente no interior da totalidade que se enclausurou num sistema coercitivo, já que lhes impede totalmente a sobrevivência.

O fracasso escolar é a não adequação a uma estrutura pré-determinada de maneira que de uma concepção de ensino totalitária, ou seja, predispõe uma maneira apenas de experienciar de uma universalidade de alunos/as e todas as suas historias de vida, escolarização, condições familiares. A educação passa na sociedade capitalista a criar uma consciência reificada delimitando a assimilação daquilo que é preciso para o sistema do capitalismo, dessa forma o que é efetivado é o semientendido e o semiexperimentado, conforme Adorno (2010, p. 29):

\footnotetext{
O entendido e experimentado medianamente - semientendido e semiexperimentado não constitui o grau elementar da formação, e sim seu inimigo mortal. Elementos que penetram na consciência sem se fundir em sua continuidade se transformam em substancias tóxicas e, tendencialmente, em superstições, até mesmo quando as criticam, da mesma maneira como aquele mestre toneleiro que, em seu desejo por algo mais elevado, se dedicou à crítica da razão pura e acabou na astrologia, evidentemente porque apenas nela seria possível unificar a lei moral que existe em nós com o céu estrelado que esta sobre nós.
}

A sociedade capitalista não permite a experiência como continuidade da consciência, ou seja, há uma distância entre o exercício da consciência e a sua associação com o real. Dessa maneira, podemos dizer que existe uma desconexão entre experiência e a formação. A experiência genuína é substituída por uma satisfação narcisista da sociedade que cultua a imagem, mesmo que, a capacidade imagética e subjetividade desta seja fadada ao ressentimento e a castração do individuo, diante da homogeneidade da totalidade. A semiformação promove uma sensação de despersonalização das pessoas e do mundo. Assim, é preciso acabar com a homogeneidade, pois, o que existe é a formulação de apenas uma história homogênia da diversidade de alunos/as que as escolas recebem, portanto, o fracasso escolar é percebido como uma causa pessoal e ineficiência do alunos/as que não conseguiram aprender.

\section{CONCLUSÃO:}

A educação deve buscar novos modelos para alcançar aqueles que fracassam. O problema é bem complexo como podemos perceber a formação aligeirada da atualidade não permite o acumulo da experiência. Na sociedade atual há um excesso de informação e ao mesmo tempo uma carência de formação. As variadas formas de informação não permitem a formação de uma identidade reflexiva, ou seja, o sujeito capaz de refletir o seu próprio mundo a sua volta. Nesse sentido, acreditamos que a discussão é bem atual e propicia ao entendimento dos novos 
- INOVAÇÃo

sujeitos da educação. $\mathrm{O}$ fracasso escolar e a formação integral devem ser problematizados juntamente, enquanto categorias validas para a busca de possíveis soluções a educação contemporânea em direção para aqueles que "fracassam". 


\section{REFERENCIAS}

ADORNO, Theodor W. A Teoria da Semiformação. In PUCCI, Bruno; ZUIN, Antonio A. S; LASTÓRIA, Luiz A. Calmon Nabuco. A Teoria Crítica e Inconformismo: novas perspectivas de pesquisa. Campinas, SP: Autores Associados, 2010.

ADORNO, Theodor W. Educação e Emancipação. Rio de Janeiro: Paz e terra, 1995.

CHARLOT, Bernard. Da relação com o saber elementos para teoria. Porto Alegre: Artes Médicas Sul, 2000.

CHARLOT, Bernard. Desafios da educação na contemporaneidade: reflexões de um pesquisador. Educação e Pesquisa, São Paulo. V. 36, p 147-161. 2010.

SILVA, Divino José da. Ética e educação para a sensibilidade em Max Horkheimer. Ijuí: Ed. UNIJUÍ, 2001. 